\title{
DON'T WASTE YOUR EMOTIONS: \\ THE IMPACT OF PRICE AND ADVERTISING APPEALS IN SERVICES
}

Bidisha Burman, Appalachian State University, USA

Pia A. Albinsson, Appalachian State University, USA

\begin{abstract}
Promoting services through advertising is different and more challenging compared to product advertising, as services possess intangible qualities (Stafford and Day 1995). Research has recognized that services require different advertising strategies than those of products (Cutler and Javalgi 1993). Assuring customers of service quality before the service experience make tangible cues important in services marketing. Even though tangible cues have been shown to be particularly important for services advertising as it can help the pre-purchase assessment of the service through the psychical representation of the attributes in the servicescape (Legg and Baker 1987; Reimer and Kuehn 2005), researchers have found that emotional appeals may result in more positive reactions from advertisements (Goldberg and Gorn 1987). Emotional appeals are thought to be more important in services compared to goods advertising since the consumption experience cannot be easily evaluated pre-purchase (Zeithaml et al. 1985). Therefore, services advertising often rely on the intangible cues found in emotional appeals.

Due to limited extant experimental research on advertising appeal effectiveness and price cues in services, we conducted two experiments in the context of hotel advertising. While past research has found support for the effectiveness of both appeals in services marketing, our first experiment showed that price level of the service may determine the effectiveness of emotional versus rational appeal. Results from the first experiment (that used four versions of a print ad), showed that rational appeal results in higher effectiveness than emotional appeal for a low priced hotel but for a higher price hotel advertisement, rational and emotional appeal did not show significant difference in influencing consumer evaluations of the offering. In order to further understand the interaction effects of rational appeals in the presence of price cues, we decided to conduct a second experiment with multiple levels of rational appeals. In this experiment, we categorized rational appeals into different levels based on the specificity of the information presented. We also examined whether the proposed effects would vary across individuals with high versus low need for cognition. In order to create a realistic experience of making hotel reservations, we developed an online stimuli consisting of different treatment versions of a hotel's webpage featuring price and the list of amenities with varying levels of specificity (for example, complimentary and surcharge information). Using appropriate scenarios, we also measured post-purchase consumer evaluations of the hotel offering.
\end{abstract}

This research contributes to the literature by extending the limited knowledge of the effect of price and advertising appeals (in both print and Internet advertising) in a services context. Examining the interaction effect of these two variables is important to hotel managers and hospitality marketers since there is a wide range of prices of hotels for consumers to choose from in most markets.

References Available Upon Request 